\title{
Impact of Abiotic Elicitors on In vitro Production of Plant Secondary Metabolites: A Review
}

\author{
Poornananda M. Naik and Jameel M. Al-Khayri* \\ Department of Agricultural Biotechnology, College of Agriculture and Food Sciences, King Faisal University, P.O. Box 420, Al-Hassa 31982, Saudi Arabia
}

Received: August 21, 2015; Accepted: December 16, 2015; Published: January 01, 2016

*Corresponding author: Jameel M. Al-Khayri, Department of Agricultural Biotechnology, College of Agriculture and Food Sciences, King Faisal University, P.O. Box 420, Al-Hassa 31982, Saudi Arabia, E-mail: jkhayri@kfu.edu.sa

\begin{abstract}
A wide variety of secondary metabolites are synthesized from primary metabolites by plants which are used for the defense purpose. The secondary metabolites had a great scope in the pharmaceuticals, food additives, flavors, and industrial applications. The secondary metabolites are accumulated in the plant body due to stress. The production of plant secondary metabolites by cultivation of plants and chemical synthesis are important agronomic and industrial objectives. The chemical synthesis in most cases has not been economically feasible. The alternative promising option is in vitro culture, which represents a potential source of bioactive compounds, but very few cultures synthesize secondary metabolites in comparison to those produced in intact plants. Elicitor is the one of the stress agent that enhances the production of secondary metabolites in a particular tissue, organs and cells. Elicitors are classified into biotic and abiotic based on their nature. In recent years the use of elicitors in the plant tissue culture has opened a new path for the production of secondary metabolite compounds. Abiotic elicitors are of non-biological origin, includes metals, light, osmotic, drought, salinity, thermal and hormonal elicitors. Abiotic elicitors have different effects on the cellular processes in the plant system, such as growth, photosynthesis, carbon partitioning, carbohydrate and lipid metabolism, osmotic homeostasis, protein synthesis, and gene expression. The present review deals with the effects of different abiotic elicitors on the production of secondary metabolites from in vitro culture.
\end{abstract}

Keywords: Abiotic Elicitor; Callus; Cell Culture; Hairy Roots; Secondary Metabolites; Stress

\section{Introduction}

Plants are the complex organisms, it forms an important part of our everyday diet and their constituents and nutritional value have been intensively studied for decades. In addition to essential primary metabolites like carbohydrates, lipids and amino acids, higher plants are also able to synthesize a number of low molecular weight compounds called the secondary metabolites. Plant secondary metabolites are the diverse group of organic compounds that are produced by plants to facilitate interaction with the biotic and abiotic environment to establish the defense mechanism [1]. Plant secondary metabolites are unique sources of pharmaceuticals, food additives, flavors and industrially important biochemicals [2]. Plants will continuously produce the novel products as well as chemical models for new drugs in the coming centuries, because the chemistry of the majority of plant species is yet to be characterized. The advent of chemical analyses and the characterization of molecular structures have helped in precisely identifying these plants and correlating them with their activity under controlled experimentation. Despite advancements in synthetic chemistry, we still depend upon biological sources for a number of secondary metabolites including pharmaceuticals.

The plant, cell, tissue and organ culture techniques have emerged as an escapable tool with the possibilities of complimenting and supplementing the conventional method in plant breeding, plant improvement and biosynthetic pathways. Plant tissue culture plays a major role in conservation of germplasm, rapid clonal propagation, regeneration of genetically manipulated superior clones, production of secondary metabolites and ex vitro conservation of valuable phytodiversity $[3,4]$. Especially, plant cell and organ cultures are promising technologies to obtain plant-specific valuable metabolites [5]. Cell and organ cultures have a higher rate of metabolism than field grown plants because the initiation of cell and organ growth in culture leads to the rapid proliferation and to a condensed biosynthetic cycle [6]. Callus induction is necessary, as the first step, in many tissue culture experiments. Callus and cell suspension can be used for long-term cell cultures maintenance. Cell suspension culture systems could be used for large scale culturing of plant cells from which secondary metabolites could be extracted. The advantage of this method is that it can ultimately provide a continuous, reliable source of natural products. Due to the limited availability and complexity of chemical synthesis, plant cell culture becomes an alternative route for large-scale production of this desired compound [7].

Recent research in the in vitro culture systems, a wide variety of elicitors have been employed in order to modify cell metabolism. These modifications are designed to enhance the productivity of useful metabolites in the cultures of the plant cells/tissues. The cultivation period in particular, can be reduced by the application of elicitors, although maintaining high concentrations of product [6]. "Elicitor is a scientifically described term for stress factors that directly or indirectly triggers the inducible defense changes 
in a plant system that results in an activation of array of protection mechanisms, including induction or expansion of biosynthesis of fine chemicals which do have a major role in the adaptation of plants to the stressful environment" [8].

\section{Classification of Elicitors}

Elicitors can be divided into two types on the basis of nature, biotic and abiotic. Biotic elicitors are the substances of biological origin, which includes polysaccharides originated from plant cell walls (chitin, pectin, cellulose, etc.) and micro-organisms. Abiotic elicitors consist of the substances that are of non-biological origin and are grouped into physical, chemical and hormonal factor. The classification of abiotic elicitor is depicted in figure 1.

\section{Abiotic Elicitors}

Abiotic elicitors have wide range of effects on the plants and in the production of secondary metabolites. The use of abiotic elicitors in plant cell cultures has received less attention compared with the biotic elicitors [9]. Recent research works explained the functions of many key genes, proteins, metabolites and molecular networks involved in plant responses to heavy metals, light, drought, salinity, thermal, hormonal and other abiotic elicitors [10]. In this review, actions of some of these elicitors are discussed in response to the production of secondary metabolites from in vitro culture.

\section{Effect on the Production of Secondary Metabolites}

Chemical Elicitors: Metals are influenced to alter the production of secondary metabolites by changing the aspects of secondary metabolism [11]. Metals have become one of the main abiotic stress agents for living organisms because of their increasing use in the developing fields like industry, agrotechnics, high bioaccumulation and toxicity [12]. Metals like $\mathrm{Ni}, \mathrm{Ag}, \mathrm{Fe}$ and Co have been shown to elicit the production of secondary metabolites in a number of plants [1]. In the cell suspension culture of Vitis vinifera the cobalt at all three used concentrations (5, 25 and $50 \mu \mathrm{M}), \mathrm{Ag}$ and $\mathrm{Cd}$ at low concentration $(5 \mu \mathrm{M})$ were most effective to stimulate the phenolic acid production, and also increasing the 3-0-glucosyl-resveratrol up to 1.6-fold of the control level after the 4 hours (h) of treatments [12].
In hairy root cultures of Ambrosia artemisiifolia, an eightfold increase of thiarubrine A production was obtained when the 16-day-old culture was challenged with $50 \mathrm{mg} / \mathrm{L}$ vanadyl sulfate $\left(\mathrm{VOSO}_{4}\right)$ for $72 \mathrm{~h}$ [13]. In an attempt to enhance betalaines production, the hairy roots were exposed to metal ions [14]. It was reported that $\mathrm{Ca}^{2+}, \mathrm{Ag}^{+}$and $\mathrm{Cd}^{2+}$ could improve the production of tropane alkaloids, scopolamine and hyoscyamine, in hairy roots cultures of Brugmansia candida [15,16]. Many kinds of heavy metal were also used as elicitors to induce accumulations of bioactive compounds in Salvia miltiorrhiza, such as $\mathrm{Co}^{2+}, \mathrm{Ag}^{+}$, $\mathrm{Cd}^{2+}, \mathrm{Cu}^{2+}, \mathrm{Ce}^{3+}, \mathrm{La}, \mathrm{Mn}^{2+}$ and $\mathrm{Zn}^{2+}$ [17-20]. Among them, $\mathrm{Ag}^{+}$was considered as an effective elicitor for phenolic compound and tanshinone production in S. miltiorrhiza hairy roots and could improve rosmarinic acid, salvianolic acid B and tanshinones production. Silver nitrate $\left(\mathrm{AgNO}_{3}\right)$ stimulated the production of tanshinone in the root culture of Perovskia abrotanoides [21]. The yields of atropine content in the Datura metel hairy roots were increased by nanosilver as an elicitor, after 12,24 and $48 \mathrm{~h}$ of the treatment [22].

Physical Elicitors: Ultrasound, light, osmotic stress, salinity, drought and thermal stress are some of the physical elicitors.

Ultrasound: The low-energy ultrasound (US) also act as an abiotic elicitor to induce plant defense mechanism and stimulate the secondary metabolite production in plants [23]. In addition, US can induce cell membrane permeabilization so as to enhance intracellular product release. This cell-permeabilizing effect may be complementary to the two-phase culture to accomplish product release from the cells and removal from the medium. Lin and $\mathrm{Wu}[24]$ reported that, the combination of US stimulation and in situ solvent extraction in a Lithospermum erythrorhizon cell culture led to 2 to 3 -fold increase in the yield of shikonin. While, in Taxus chinensis 1.5 to 1.8-fold increase in taxol yield with 2 minutes (min) US treatment once or twice during a weekculture period was achieved [25]. In Taxus baccata cell culture the amount of taxol was increased by 3 times when treated with US [26], and ginsenoside saponins enhanced by $75 \%$ in Panax ginseng cell culture [27].

Light: The light is a physical factor which can affect the metabolite production in plants. Light can stimulate secondary

$\begin{array}{lll} & \text { Abiotic elicitor } \\ \text { Light } & \text { Heavy metals } & \text { Hormonal } \\ \text { Thermal stress } & \text { Mineral salts } & \text { Salicylic acid } \\ \text { Salt stress } & \text { Gaseous toxins } \\ \text { Drought } & & \\ \text { Osmotic stress } & & \end{array}$

Figure 1: Classification of abiotic elicitors based on their nature. 
metabolites include gingerol and zingiberene production in Zingiber officinale callus culture [28]. Light plays a role in both growth and secondary metabolite production in the hairy roots. Sauerwein et al. [29] found that the alkaloid content of both normal and hairy roots of Hyoscyamus albus was greater in roots grown in the light compared to roots grown in the dark. The study of Yu et al. [30] in P. ginseng hairy roots also showed that the exposure of hairy roots to different light spectral ranges affected growth and metabolite biosynthesis. The light induced the growth as well as indole alkaloid production in the hairy root cultures of Catharanthus roseus [31]. The effect of light irradiation influenced artemisinin biosynthesis in hairy roots of Artemisia annua [32] .

Ultraviolet (UV) light acts as an abiotic factor which stimulates the biosynthesis of secondary metabolites [33]. UV radiation is divided into three regions: UV-C (wavelengths below $280 \mathrm{~nm}$ ), UV-B (280- $315 \mathrm{~nm}$ ) and UV-A (315-400 nm). UV-C is the most damaging, but it is almost completely absorbed by the stratosphere. By contrast, UV-B radiation is only partially absorbed by the stratospheric ozone layer and UV-A is not at all absorbed. UV-B radiation was exclusively seen as a stress factor, UV-B trigger distinct changes in the plant's secondary metabolism resulting in an accumulation of phenolic compounds such as flavonoids and glucosinolates [33]. UV-B irradiation induced a rise of nitric oxide (NO) production, activities of nitric oxide synthase and phenylalanine ammonia lyase (leading to flavonoid synthesis), as well as flavonoid level in Ginkgo biloba callus [34]. Ramani and Jayabaskaran [35] reported enhanced catharanthine and vindoline production in suspension cultures of $C$. roseus by UV-B light. UV-B elicited an increase in the total terpenoid indole alkaloids (TIAs) concentrations in C. roseus hairy roots [36]. High doses of artificial UV-B radiation modified the antioxidant content by increasing the content of vitamin $\mathrm{C}$ and decreased the phenolic content of in vitro cultured Turnera diffusa plants [37]. Ku et al. [38] reported that synthesis of resveratrol and piceatannol were promoted by UV-C radiation in callus cultures of peanut. UV-C irradiation is an effective method to enhance stilbene production in grape calli of different genotypes [39]. UV-C together with methyl jasmonate (MeJA) or salicylic acid (SA) also used to enhance stilbene production in $V$. vinifera cell cultures [40].

Osmotic, Salt and Drought Stress: Osmotic stress is an important abiotic elicitor affecting plant growth, development, morphogenesis and the formation of secondary metabolites [41]. Sucrose is a typical osmotic stress agent used for the induction of water stress in plants that also serves as a vital carbon and energy source. The influence of osmotic stress enhanced the accumulation of capsaicin in cell suspension cultures of Capsicum chinensis [42]. It also enhanced the production of steviol glycosides content in both callus as well as suspension culture of Stevia rebaudiana [43].

Plants have developed complex mechanisms for adaptation to the osmotic, ionic and oxidative stresses that are induced by the salt stress. Exposure to salinity is known to induce or stimulate production of secondary plant products, such as phenols, terpenes and alkaloids $[44,45]$. The salt stress decreased the anthocyanin level in the salt-sensitive species [46]. The effect of $\mathrm{KCl}$ and $\mathrm{CaCl}_{2}$ induced stress on in vitro cultures of Bacopa monnieri enhanced the accumulation of medicinally important bacoside A content [47]. An improved synthesis of vinblastine and vincristine was observed in C. roseus embryogenic tissue culture by using sodium chloride $(\mathrm{NaCl})$ as an elicitor [48]. In Nitraria tangutorum cell suspension the increased sitosterol content was observed at $250 \mathrm{mM} \mathrm{NaCl}$ treatment [49]. Small increase of the canavanine content in Sutherlandia frutescens in vitro shoot culture growing on $100 \mathrm{mM} \mathrm{NaCl}$ medium was detected, indicating that salinity stress was not a major limitation on cavanine production [50].

The drought is an important stress factor limiting the plant growth, reproductive development and finally survival. Drought stress tolerance is seen in all plants, but its extent varies from species to species. Plants which are exposed to drought stress frequently were affected the synthesis and accumulation of secondary metabolite contents [51]. A weak water deficit greatly increased the glycyrrhizic acid content in roots of Glycyrrhiza uralensis [52]. The drought stress was induced by polyethylene glycol (PEG), when it was treated to in vitro grown date palm callus, the proline content was increased gradually in response to increasing PEG-concentration. At higher concentration (30\%) accumulation of proline started to decline as an indication of disturbance of physiological system [53]. PEG as a supplement had little to no effect on canavanine synthesis in Sutherlandia frutescens in vitro shoot culture [50].

Thermal Stress: Extreme temperature is an adverse environmental factor limiting growth and productivity of plants, it also hinders the plant growth by manipulating various metabolic processes including synthesis and degradation of primary metabolites [54]. Temperature range of $17-25^{\circ} \mathrm{C}$ is normally used for the induction of callus tissues and growth of cultured cells [6]. The Melastoma malabathricum cell cultures incubated at a lower temperature range $\left(20 \pm 2^{\circ} \mathrm{C}\right)$ grew better and had higher anthocyanin production than those grown at $26 \pm$ $2{ }^{\circ} \mathrm{C}$ and $29 \pm 2^{\circ} \mathrm{C}$ [55]. Optimum temperature $\left(25^{\circ} \mathrm{C}\right)$ maximizes the anthocyanin yield as demonstrated in cell cultures of Perilla frutescens [56] and strawberry [57]. Although temperature around $25^{\circ} \mathrm{C}$ is normally used for hairy root cultures, lowering the cultivation temperature $\left(19.5^{\circ} \mathrm{C}\right)$ increased the proportion of linolenic acid and the total content of indole alkaloids in $C$. roseus hairy roots [58] A 5C increase in temperature significantly increased the ginsenoside content in roots of Panax quinquefolius [59].

\section{Hormonal Elicitors:}

Salicylic Acid: Salicylic acid is the one of the important abiotic elicitor, which has the capability to induce the secondary metabolites from in vitro cultures. SA induced the stilbene production in the cell suspension of $V$. vinifera [40]. A high concentration of $200 \mu \mathrm{M}$ SA was required to induce substantial quantities of gymnemic acid in the suspensions that reached a maximum after $48 \mathrm{~h}$ treatment. The SA induced response towards gymnemic acid accumulation resulted in a 4.9-fold 
increase in comparison to the control cultures [60]. In the cell culture of $S$. miltiorrhiza, the different concentrations of the SA were affected the accumulation of salvianolic acid B and of caffeic acid. Both phenolic acid accumulations were significantly increased at 8 and $96 \mathrm{~h}$ after the applications of 3.125-25 mg/L of SA, but were significantly less with $32-50 \mathrm{mg} / \mathrm{L}$ of SA. After the $96 \mathrm{~h}$ treatments with $3.125-25 \mathrm{mg} / \mathrm{L}$ of SA, the concentration of the phenolic acids decreased significantly compared to the amount $8 \mathrm{~h}$ after the treatments, but were still higher than that of the control [61]. SA with transgenic technology, highly enhanced the production of tanshinones in S. miltiorrhiza hairy roots [62]. Optimum production of withanolide A, withanone and withaferin A were reported in the elicited-hairy roots of Withania somnifera [63]

Jasmonates: Jasmonic acid has been proposed as key compounds of the signal transduction pathway involved in the elicitation of secondary metabolite biosynthesis which takes part in plant defense reactions [64]. The application of a twostage culture system with a combined treatment of mannitol $(2 \mathrm{mM})$ and JA $(40 \mu \mathrm{M})$ resulted in the optimum accumulation of resveratrol in the callus biomass of $V$. vinifera [65]. JA and its more active derivative MeJA can trigger the production of a wide range of plant secondary metabolites such as rosmarinic acid terpenoid indole alkaloid and plumbagin in various cell cultures [66-68]. JA and MeJA have been used as elicitors for stilbene biosynthesis in $V$. vinifera cell cultures $[69,70]$. The treatment of MeJA to $V$. vinifera cell cultures also promoted anthocyanin accumulation [71]. In the cell culture of Andrographis paniculata, the MeJA induced the optimum accumulation of andrographolide at $24 \mathrm{~h}$ compared with 48 and $72 \mathrm{~h}$ of treatments [72]. In the $V$. vinifera cell system, a rapid accumulation of trans-resveratrol was recorded with MeJA treatement, starting from $2 \mathrm{~h}$ and reaching its maximum value at $96 \mathrm{~h}$ [70].

In a study, JA elicitation is reported to enhance the production of plumbagin in hairy root culture of Plumbago indica [73]. JA and MeJA have been used as elicitors for stilbene biosynthesis in Vitis rotundifolia hairy root cultures [74]. MeJA with transgenic technology, highly enhanced the production of tanshinones in S. miltiorrhiza hairy roots [62]. In the hairy root culture of W. somnifera, MeJA elicited the production of withanolide A, withanone and withaferin A [63]. The root cultures of Taverniera cuneifolia treated with different concentrations of MeJA, the glycyrrhizic acid content increased gradually with an increase in MeJA (1-100 $\mu \mathrm{M})$ concentration. Approximately 2.5-fold elevation in glycyrrhizic acid production was noticed in MeJA $(100 \mu \mathrm{M})$ treated roots, when compare to the control. However, further increase in MeJA $(1000 \mu \mathrm{M})$ concentration resulted in the decrease of glycyrrhizic acid production [75]. The MeJA enhanced the production of bacoside $\mathrm{A}$, a valuable triterpenoid saponin having nootropic therapeutic activity in in vitro shoot cultures of B. monnieri [76].

\section{Conclusion}

The evolutionary process made plant to produce new bioactive compounds time to time. The plant produces a number of secondary metabolites in varying concentration in different parts of the tissue. For more than three decades an in vitro culture plays an important role in the production of secondary metabolites from the particular tissue, organ and cells. In the past, less attention was paid to abiotic elicitor, but now the use of abiotic elicitors has emerged as one of the most effective strategy for enhancing the productivity of different commercial secondary metabolites from in vitro cultures. Though, elicitation enhances secondary metabolism in in vitro culture of plant cells/organ, but the exact mechanism of elicitationis still not fully understood. Moreover, molecular and biosynthetic pathway of the secondary metabolites should be understood and extensive research must be carried out in this way to determine the optimum conditions for each specific medicinal plant to enhance the secondary metabolites.

\section{References}

1. Wang JW, Wu JY. Effective elicitors and process strategies for enhancement of secondary metabolite production in hairy root cultures. Adv Biochem Eng Biotechnol. 2013; 134: 55-89. doi: 10.1007/10_2013_183.

2. Murthy HN, Lee EJ, Paek KY. Production of secondary metabolites from cell and organ cultures: strategies and approaches for biomass improvement and metabolite accumulation. Plant Cell Tiss Org Cult. 2014; 118: 1-16.

3. Anis M, Husain MK, Faisal M, et al. In vitro approaches for plant regeneration and conservation of some medicinal plants. In: Kumar A, Sopory SK, editors. Recent advances in plant biotechnology and its application. New Delhi: IK International Pvt. Ltd; 2009. p. 397-410.

4. Anis M, Husain MK, Siddique, I, et al. Biotechnological approaches for the conservation of forestry species. In: Jenkins JA. editor. Forest decline: causes and impacts. USA: Nova Science Publishers Inc; 2011. p. 1-39.

5. Kehie M, Kumaria S, Tandon P, Ramchiary N. Biotechnological advances on in vitro capsaicinoids biosynthesis in capsicum:a review. Phytochem Rev.2015; 14(2): 189-201. doi: 10.1007/s11101-0149344-6.

6. Rao SR, Ravishankar GA. Plant cell cultures: Chemical factories of secondary metabolites. Biotechnol Adv. 2002; 20(2): 101-53.

7. Savitha BC, Timmaraju R, Bhagyalaksami N, Ravishankar GA. Different biotic and abiotic elicitors influence betalain production in hairy root cultures of Beta vulgaris in shake flask and bioreactor. Process Biochem. 2006; 41: 50-60.

8. Goel MK, Mehrotra S, Kukreja AK. Elicitor-induced cellular and molecular events are responsible for productivity enhancement in hairy root cultures: an insight study. Appl Biochem Biotechnol. 2011; 165(5-6): 1342-55. doi: 10.1007/s12010-011-9351-7.

9. Radman R, Saez T, Bucke C, Keshavarz T. Elicitation of plants and microbial cell systems. Biotechnol Appl Biochem. 2003; 37(Pt 1): 91102.

10. Rodziewicz P, Swarcewicz B, Chmielewska K, Wojakowska A, Stobiecki $\mathrm{M}$. Influence of abiotic stresses on plant proteome and metabolome changes. Acta Physiol Plant. 2014; 36: 1-19.

11. Nasim SA1, Dhir B. Heavy metals alter the potency of medicinal plants. Rev Environ Contam Toxicol. 2010; 203: 139-49. doi: 10.1007/9781-4419-1352-4_5. 
12. Cai Z, Kastell A, Speiser C, SmetanskaI. Enhanced resveratrol production in Vitis vinifera cell suspension cultures by heavy metals without loss of cell viability. Appl Biochem Biotechnol. 2013 Sep;171(2):330-40. doi: 10.1007/s12010-013-0354-4.

13. Bhagwath SG, Hjortsø MA. Statistical analysis of elicitation strategies for thiarubrine A production in hairy root cultures of Ambrosia artemisiifolia. J Biotechnol. 2000; 80(2): 159-167.

14. Rudrappa T, Neelwarne B, Aswathanarayana RG. In situ and ex situ adsorption and recovery of betalains from hairy root cultures of Beta vulgaris. Biotechnol Progr. 2004; 20(3): 777-85.

15. Pitta-Alvarez SIP, Spollansky TC, Giulietti AM. The influence of different biotic and abiotic elicitors on the production and profile of tropane alkaloids in hairy root cultures of Brugmansia candida. Enzym Microb Technol. 2000; 26(2-4): 252-8.

16. Angelova Z, Georgiev S, Roos W. Elicitation of plants. Biotechnol Biotechnol Equip. 2006; 20(2): 72-83.

17. Yan Q, Shi M, NgJ, Wu JY.Elicitor-induced rosmarinic acid accumulation and secondary metabolism enzyme activities in Salvia miltiorrhiza hairy roots. Plant Sci. 2006; 170(4): 853-8.

18. Zhao JL, Zhou LG, Wu JY. Effects of biotic and abiotic elicitors on cell growth and tanshinone accumulation in Salvia miltiorrhiza cell cultures. Appl Microbiol Biotechnol. 2010; 87(1): 137-44. doi: 10.1007/s00253-010-2443-4.

19. Zhou J, Fang L, Wang X, Guo LP, Huang LQ. La dramaticaly enhances the accumulation of tanshinones in Salvia miltiorrhiza hairy root cultures. Earth Sci Res. 2013; 2(1): 187-192.

20. Shi M, Luo X, Ju G, Yu X, Hao X, Huang Q, et al. Increased accumulation of the cardio-cerebrovascular disease treatment drug tanshinone in Salvia miltiorrhiza hairy roots by the enzymes 3-hydroxy-3methylglutaryl CoA reductase and 1-deoxy-D-xylulose 5-phosphate reductoisomerase. Funct Integr Genomics. 2014; 14(3): 603-15. doi 10.1007/s10142-014-0385-0.

21. Arehzoo Z, Christina S, Florian G, Parvaneh A, Javad A, Seyed H, et al. Effects of some elicitors on tanshinone production in adventitious root cultures of Perovskia abrotanoides Karel. Ind Crops Prod. 2015 67: 97-102.

22.Zahra S, Mehrnaz K, Gholamreza A, Mustafa G. Improvement of atropine production by different biotic and abiotic elicitors in hairy root cultures of Datura metel. Turk J Biol. 2015; 39: 111-118.

23. Yu M, Liu H, Shi A, Liu L, Wang Q. Preparation of resveratrol-enriched and poor allergic protein peanut sprout from ultrasound treated peanut seeds. Ultrason Sonochem. 2016; 28: 334-40. doi: 10.1016/j. ultsonch.2015.08.008.

24. Lin L, Wu J. Enhancement of shikonin production in single and twophase suspension cultures of Lithospermum erythrorhizon cells using low-energy ultrasound. Biotechnol Bioeng. 2002; 78(1):81-8.

25. Wu J, Lin L. Enhancement of taxol production and release in Taxus chinensis cell cultures by ultrasound, methyl jasmonate and in situ solvent extraction. Appl Microbiol Biotechnol. 2003; 62(2-3):151155

26. Rezaei A, Ghanati F, Dehaghi MA. Stimulation of taxol production by combined salicylic acid elicitation and sonication in Taxus baccata cell culture. In: 2011 International Conference on Life Science and Technology IPCBEE; 2011. p. 193-7.

27. Lin L, Wu J, Ho KP, Qi S. Ultrasound-induced physiological effects and secondary metabolite (saponin) production in Panax ginseng cell cultures. Ultrasound Med Biol. 2001; 27(8): 1147-52.

28. Anasori P, Asghari G. Effects of light and differentiation on gingerol and zingiberene production in callus culture of Zingiber officinale Rosc. Res Pharm Sci. 2008; 3(1): 59-63.

29. Sauerwein M, Wink M, Shimomura K. Influence of light and phytohormones on alkaloid production in transformed root cultures of Hyoscyamus albus. J Plant Physiol. 1992; 140(2): 147-52.

30.Yu KW, Murthy HN, Hahn EJ, Paek KY. Ginsenoside production by hairy root cultures of Panax ginseng: influence of temperature and light quality. Biochem Eng J. 2005; 23(1): 53-56.

31. Bhadra R, Morgan JA, Shanks JV. Transient studies of light-adapted cultures of hairy roots of Catharanthus roseus: Growth and indole alkaloid accumulation. Biotechnol Bioeng. 1998; 60(6): 670-8.

32. Liu CZ, Guo C, Wang Y, Ouyang F. Effect of light irradiation on hairy root growth and artemisinin biosynthesis of Artemisia annua L. Process Biochem.2002; 38(4): 581-5.

33. Schreiner M, Mewis I, Neugart S, Zrenner R, Glaab J, Wiesner M, et al. UV-B Elicitation of secondary plant metabolites. In: Kneissl M, Rass J,editors. III-Nitride ultraviolet emitters. Springer series in materials science 227. Springer International Publishing, Switzerland: p. 387 414. doi: 10.1007/978-3-319-24100-5_14.

34. Hao G, Du X, Zhao F, Shi R, Wang J. Role of nitric oxide in UV-B-induced activation of PAL and stimulation of flavonoid biosynthesis in Ginkgo biloba callus. Plant Cell Tiss Org Cult. 2009; 97(2): 175-85.

35. Ramani S, Jayabaskaran C. Enhanced catharanthine and vindoline production in suspension cultures of Catharanthus roseus by ultraviolet-B light. J Mol Signal. 2008; 3: 9. doi: 10.1186/1750-21873-9.

36. Binder BY, Peebles CA, Shanks JV, San KY. The effects of UV-B stress on the production of terpenoid indole alkaloids in Catharanthus roseus hairy roots. Biotechnol Prog. 2009; 25(3): 861-5. doi: 10.1002/ btpr.97.

37. Soriano-Melgar Lde A, Alcaraz-Meléndez L, Méndez-Rodríguez LC, Puente ME, Rivera-Cabrera F, Zenteno-Savín T. Antioxidant responses of damiana (Turnera diffusa Willd) to exposure to artificial ultraviolet (UV) radiation in an in vitro model; part II; UV-B radiation. Nutr Hosp. 2014; 29(5): 1116-22. doi: 10.3305/nh.2014.29.5.7092.

38. Ku KL, Chang PS, Cheng YC, Lien CY. Production of stilbenoids from the callus of Arachis hypogaea: a novel source of the anticancer compound piceatannol. J Agric Food Chem. 2005; 53(10): 3877-81.

39. Liu W, Chunyan Liu, Chunxiang Yang, Lijun Wang, Shaohua Li. Effect of grape genotype and tissue type on callus growth and production of resveratrols and their piceids after UV-C irradiation. Food Chem.2010; 122(3): 475-484

40.Xu A, Zhan JC, Huang WD. Effects of ultraviolet C, methyl jasmonate and salicylic acid, alone or in combination, on stilbene biosynthesis in cell suspension cultures of Vitis vinifera L. cv. Cabernet Sauvignon. Plant Cell Tiss Org Cult. 2015; 122(1): 197-211.

41. Liu CZ, Cheng XY. Enhancement of phenylethanoid glycosides biosynthesis in cell cultures of Cistanche deserticola by osmotic stress. Plant Cell Rep. 2008; 27(2): 357-62.

42. Kehie M1, Kumaria S, Tandon P. Osmotic stress induced-capsaicin production in suspension cultures of Capsicum chinense Jacq.cv. Naga King Chili. Bioprocess Biosyst Eng. 2014; 37(6): 1055-63. doi: 10.1007/s00449-013-1076-2.

43. Gupta P, Sharma S, Saxena S.. Biomass yield and steviol glycoside 
production in callus and suspension culture of Stevia rebaudiana treated with proline and polyethylene glycol. Appl Biochem Biotechnol. 2015; 176(3): 863-74. doi: 10.1007/s12010-015-1616-0.

44. Selmar D. Potential of salt and drought stress to increase pharmaceutical significant secondary compounds in plants. Agr Forest Res. 2008; 58: 139-144.

45. Haghighi Z, Karimi N, Modarresi M, Mollayi S. Enhancement of compatible solute and secondary metabolites production in Plantago ovata Forsk. by salinity stress. J Med Plants Res. 2012; 6(18): 34953500 .

46. Daneshmand F, Arvin MJ, Kalantari KM. Physiological responses to $\mathrm{NaCl}$ stress in three wild species of potato in vitro. Acta Physiol Plant 2010; 32(1): 91-101.

47. Ahire ML, Laxmi S, Walunj PR, Kavi Kishor PB, Nikam TD. Effect of potassium chloride and calcium chloride induced stress on in vitro cultures of Bacopa monnieri (L.) Pennell and accumulation of medicinally important bacoside A. J Plant Biochem Biotechnol. 2014; 23(4): 366-378. doi: 10.1007/s13562-013-0220-z.

48. Fatima S, Mujib A, Dipti T. $\mathrm{NaCl}$ amendment improves vinblastine and vincristine synthesis in Catharanthus roseus: a case of stress signalling as evidenced by antioxidant enzymes activities. Plant Cell Tiss Org Cult. 2015; 121(2): 445-458.

49. Ni J, Yang X, Zhu J, Liu Z, Ni Y, Wu H, et al. Salinity-induced metabolic profile changes in Nitraria tangutorum Bobr. suspension cells. Plant Cell Tiss Org Cult. 2015; 122(1): 239-48. doi: 10.1007/s11240-0150744-0.

50. Colling J, Stander MA, Makunga NP. Nitrogen supply and abiotic stress influence canavanine synthesis and the productivity of in vitro regenerated Sutherlandia frutescens microshoots. J Plant Physiol. 2010; 167(17): 1521-4. doi: 10.1016/j.jplph.2010.05.018.

51.Al-Gabbiesh A, Kleinwächter M, Selmar D. Influencing the contents of secondary metabolites in spice and medicinal plants by deliberately applying drought stress during their cultivation. Jordan J Biol Sci. 2015; 8(1):1-10.

52. Li W, Hou J, Wang W, Tang X, Liu C, Xing D. Effect of water deficit on biomass production and accumulation of secondary metabolites in roots of Glycyrrhiza uralensis. Russ J Plant Physiol. 2011; 58(3): 538542

53. Al-Khayri JM, Ibraheem Y. In vitro selection of abiotic stress tolerant date palm (Phoenix dactylifera L.): A review. Emir J Food Agric. 2014; 26(11): 921-933.

54. Xu Y, Du H, Huang B. Identification of metabolites associated with superior heat tolerance in thermal bentgrass through metabolic profiling. CropSci. 2013; 53: 1626-1635.doi:10.2135/ cropsci2013.01.0045.

55. Chan LK, Koay SS, Boey PL, Bhatt A. Effects of abiotic stress on biomass and anthocyanin production in cell cultures of Melastoma malabathricum. Biol Res. 2010; 43: 127-35. PMID: 21157639.

56.Zhong JJ, Yoshida T. Effects of temperature on cell growth and anthocyanin production in suspension cultures of Perilla frutescen. J Ferment Bioeng. 1993; 76(6): 530-1.

57.Zhang W, Seki M, Furusaki S. Effect of temperature and its shift on growth and anthocyanin production in suspension cultures of strawberry cells. Plant Sci. 1997; 127(2): 207-214.

58. Toivonen L, Laakso S, Rosenqvist $\mathrm{H}$. The effect of temperature on hairy root cultures of Catharanthus roseus: growth, indole alkaloid accumulation and membrane lipid composition. Plant Cell Rep. 1992;

\section{1(8): 395-9. doi: 10.1007/BF00234368.}

59. Jochum GM, Mudge KW, Thomas RB. Elevated temperatures increase leaf senescence and root secondary metabolite concentration in the understory herb Panax quinquefolius (Araliaceae). Am J Bot. 2007; 94(5): 819-26. doi: 10.3732/ajb.94.5.819.

60. Chodisetti B, Rao K, Gandi S, GiriA. Gymnemic acid enhancement in the suspension cultures of Gymnema sylvestre by using the signaling molecules-methyl jasmonate and salicylic acid. In Vitro Cell Dev BiolPlant. 2015; 51(1): 88-92.

61. Dong J, Wan G, Liang Z. Accumulation of salicylic acid-induced phenolic compounds and raised activities of secondary metabolic and antioxidative enzymes in Salvia miltiorrhiza cell culture J Biotechnol. 2010; 148(2-3): 99-104. doi: 10.1016/j.jbiotec.2010.05.009.

62. Hao X, Shi M, Cui L, Xu C, Zhang Y, Kai G. Effects of methyl jasmonate and salicylic acid on tanshinone production and biosynthetic gene expression in transgenic Salvia miltiorrhiza hairy roots. Biotechnol Appl Biochem. 2015; 62(1): 24-31. doi: 10.1002/bab.1236.

63. Sivanandhan G, Arun M, Mayavan S, Rajesh M, Jeyaraj M, Dev GK, et al. Increased production of withanolide $\mathrm{A}$, withanone, and withaferin A in hairy root cultures of Withania somnifera (L.) Dunal elicited with methyl jasmonate and salicylic acid. Appl Biochem Biotechnol. 2012; 168(3): 681-96. doi: 10.1007/s12010-012-9809-2.

64. Jeandet P, Douillet-Breuil AC, Bessis R, Debord S, Sbaghi M, Adrian M. Phytoalexins from the Vitaceae: biosynthesis, phytoalexin gene expression in transgenic plants, antifungal activity, and metabolism. J Agric Food Chem. 2002; 50(10): 2731-41.

65. Raluca M, Sturzoiu C, Florenta H, Aurelia B, Gheorghe S. Biotic and abiotic elicitors induce biosynthesis and accumulation of resveratrol with antitumoral activity in the long - term Vitis vinifera L. callus cultures. Roman Biotechnol Lett. 2011; 16(6): 6683-9.

66. Krzyzanowska J, Czubacka A, Pecio L, Przybys M, Doroszewska T, Stochmal A, et al. The effects of jasmonic acid and methyl jasmonate on rosmarinic acid production in Mentha piperita cell suspension cultures. Plant Cell Tiss Org Cult. 2012; 108(1): 73-81.

67. Almagro L, Gutierrez J, Pedreño MA, Sottomayor M. Synergistic and additive influence of cyclodextrins and methyl jasmonate on the expression of the terpenoid indole alkaloid pathway genes and metabolites in Catharanthus roseus cell cultures. Plant Cell TissOrg Cult. 2014; 119(3): 543-51.

68. Silja PK, Gisha GP, Satheeshkumar K. Enhanced plumbagin accumulation in embryogenic cell suspension cultures of Plumbago rosea L. following elicitation. Plant Cell Tiss Org Cult. 2014; 119: 46977.

69. Tassoni A, Fornalè S, Franceschetti M, Musiani F, Michael AJ, Perry B, et al. Jasmonates and Na-orthovanadate promote resveratrol production in Vitis vinifera cv. Barbera cell cultures. New Phytol. 2005; 166(3): 895-905.

70. Taurino M, Ingrosso I, D’amico L, De Domenico S, Nicoletti I, Corradini D, et al. Jasmonates elicit different sets of stilbenes in Vitis vinifera cv. Negramaro cell cultures. Springerplus. 2015; 4: 49. doi: 10.1186/ s40064-015-0831-z.

71. Tassoni A, Durante L, Ferri M. Combined elicitation of methyljasmonate and red light on stilbene and anthocyanin biosynthesis. J Plant Physiol. 2012; 169(8): 775-81. doi: 10.1016/j.jplph.2012.01.017.

72. Sharma SN, Jha Z, Sinha RK, Geda AK. Jasmonate-induced biosynthesis of andrographolide in Andrographis paniculata. Physiol Plant. 2015; 153(2): 221-9. doi: 10.1111/ppl.12252. 
73. Gangopadhyay M, Dewanjee S, Bhattacharya S. Enhanced plumbagin production in elicited Plumbago indica hairy root cultures. J Biosci Bioeng. 2011; 111(6): 706-10. doi: 10.1016/j.jbiosc.2011.02.003.

74. Nopo-Olazabal C, Condori J, Nopo-Olazabal L, Medina-Bolivar F Differential induction of antioxidant stilbenoids in hairy roots of Vitis rotundifolia treated with methyl jasmonate and hydrogen peroxide. Plant Physiol Biochem. 2014; 74: 50-69. doi: 10.1016/j. plaphy.2013.10.035.
75. Awad V, Kuvalekar A, Harsulkar A. Microbial elicitation in root cultures of Taverniera cuneifolia (Roth)Arn. for elevated glycyrrhizic acid production. Ind Crops Prod. 2014; 54: 13-6.

76. Sharma P, Yadav S, Srivastava A, Shrivastava N. Methyl jasmonate mediates upregulation of bacoside A production in shoot cultures of Bacopa monnieri. Biotechnol Lett. 2013; 35(7): 1121-5. doi: 10.1007/ s10529-013-1178-6. 